ARTIGOS

\section{ANÁLISE DO PERFIL DOS SERVIDORES TÉCNICO-ADMINISTRATIVOS DE UMA IFE APÓS A PROMULGAÇÃO DA LEI FEDERAL 11.091/2005}

\section{RESUMO}

Desde a percepção do trabalhador como diferencial competitivo, as organizações passaram a buscar sua motivação e desenvolvimento. As instituições federais de ensino desenvolveram planos de carreira, objetivando capacitar e qualificar seus servidores, diante da maior efetividade de suas ações. O objeto deste trabalho é o perfil dos TAE da UFSJ, 12 anos após a promulgação da Lei Federal 11.091/2005, que concede incentivos financeiros conforme a obtenção de titulações superiores às exigidas para o ingresso nos cargos. Este levantamento é uma pesquisa descritiva, que realizou análise quanti-qualitativa dos dados extraídos de sistemas informatizados utilizados pela Universidade. Observou-se que a supramencionada Lei influenciou os servidores ingressantes a partir de 2005 a buscar maiores níveis de instrução, embora não tenha sido capaz de fazê-lo com os que já estavam no serviço público nesta ocasião, o que leva a inferir que tem havido uma mudança gradual na cultura dessas instituições.

Palavras-chave: Qualificação. Plano de carreira. Servidor técnico-administrativo em educação.

\section{INTRODUÇÃO}

O Estado é composto de elementos materiais (a população e o território), formais (ordenamento jurídico e governo soberano) e o bem comum (instrumento de evolução e aperfeiçoamento social). A priori, é um acordo informal da vontade de união perpétua das partes. Somente em um segundo momento é formalizado pelas leis. A partir da constitucionalização do Estado, este passa a ser obrigado a prestar determinados serviços à população e esta a ter também obrigações compulsórias, como o pagamento de impostos, imprescindíveis para a manutenção da máquina pública, gerenciada pela administração pública (SLOMSKI, 2005).

$\mathrm{Na}$ busca de se atingir maior eficácia em suas ações gerenciais, governos de todo o mundo buscam observar novos padrões de qualidade na prestação de serviços à sociedade, levando-os, também, a buscar novos papéis a serem desempenhados pelos agentes públicos (DENHARDT; DENHARDT, 2000). Esta busca enviesa- 
da desencadeia uma maior instrumentalização da gestão em si e, em menor escala, preocupa-se com os fatores sociopolíticos existentes e importantes, criando um descompasso em diversas dimensões, dentre as quais cita-se a dimensão institucional-administrativa, principalmente no que se refere às dificuldades geradas na profissionalização dos servidores do setor público quando no seu trabalho (PAULA, 2007).

Macedo e Pires (2006) afirmam que o descrédito quanto ao serviço público sério e de qualidade faz que irrompa a necessidade de novas formas de gestão, tendo em vista o atendimento dos princípios constitucionais e o adequado emprego dos recursos públicos.

Assim, neste início de milênio, atento à evolução dos métodos de gestão e primando pelo atendimento dos interesses da sociedade cada vez mais exigente e participativa, o Estado brasileiro começa a implementar políticas diversas, com o intuito de ofertar melhores serviços aos cidadãos. Para tal, torna-se fundamental a busca pela mudança cultural nas instituições e a consequente reformulação da máquina pública. Muito embora já se observem grandes avanços, sobremaneira no que se refere à transparência e à divulgação de atos e informações de interesse público (TORRES, 2004), muito ainda há de se fazer, sobretudo no que tange aos programas de desenvolvimento dos quadros de pessoal destas instituições (SARAIVA, 2002).

$\mathrm{Na}$ área da educação, a transição atual exigiu quadros de pessoal capacitado e qualificado (DONAZAR, 2015), razão pela qual somaram-se esforços do Governo Federal e das Instituições Federais de Ensino (IFE) vinculadas ao Ministério da Educação (MEC), no sentido de desenvolvê-los, com o fim de aumentar a efetividade das atividades de ensino, pesquisa e extensão por elas desenvolvidas. Recentemente, o Governo Federal buscou a expansão do acesso à educação superior pela população brasileira. Para tal, instituiu programas como o Programa Universidade para Todos (PROUni), que estabelece diretrizes para a inserção de pessoas de baixa renda em instituições de ensino privadas, por meio da concessão de bolsas de estudo nas modalidades parcial e integral (BRASIL, 2005a), e o Programa de Apoio a Planos de Reestruturação e Expansão das Universidades Federais (REUni), cujo objetivo é o aumento do número de egressos dos cursos de graduação presencial, por meio da ampliação das condições de acesso e permanência deles. (BRASIL, 2007).

O REUni exigiu das IFE não apenas um incremento estrutural, mas também o aumento de servidores públicos qualificados, visando dar suporte ao maior número de vagas ofertadas à sociedade. Neste cenário, são aprovadas novas legislações, visando à adequação das carreiras de docentes e técnicos administrativos à nova realidade e suas exigências. A Lei Federal 11.091/2005 (BRASIL, 2005b), bem como legislações complementares, define o Plano de Carreira dos Cargos Técnico-Administrativos em Educação e prevê, entre outras questões, o aumento salarial desses servidores por meio de progressões na carreira ou quando da obtenção de novos níveis de escolaridade.

Entretanto, no Brasil, o foco das pesquisas voltadas para a administração pública se deu, em maior intensidade, para o momento de elaboração de programas e políticas, e não para a ocasião de sua implementação e avaliação; somente após a década de 1980, este cenário tem-se alterado, sendo que tal mudança é atribuída às transformações verificadas na sociedade e no Estado brasileiro (COSTA; CASTANHAR, 2003).

Para Arretche (1999), a avaliação de políticas públicas é essencial na medida em que institui instrumentos técnicos de mensuração de sua efetividade, de forma a minimizar ou eliminar as interferências subjetivas na atribuição de uma relação de causalidade entre um programa e um resultado, ou da inexistência de um ou outro, possibilitando a correção e o redesenho da política pelo gestor, bem como a participação social e democrática nos processos de tomada de decisão. Todo este cenário gera um diapasão entre a legislação vigente, as teorias administrativas e a operacionalidade das instituições públicas. Este estudo insere-se nesta la- 
cuna, observada a partir da promulgação da Lei Federal 11.091/2005 (BRASIL, 2005b).

Diante da relevância das políticas públicas voltadas para a educação superior e técnica no Brasil, por serem as IFE as provedoras de profissionais qualificados para o mercado e ante os fatos apontados, o presente trabalho consiste em um levantamento descritivo, com análise quanti-qualitativa dos dados. Assim, diante da promulgação da Lei Federal 11.091/2005 (BRASIL, 2005b), e partindo-se do pressuposto de que o trabalhador busca sua qualificação também e principalmente tendo em vista o retorno financeiro, este estudo se propõe a investigar a influência da Lei em tela sobre o nível de escolaridade dos servidores técnico-administrativos em educação (TAE) de uma instituição federal de ensino superior de Minas Gerais, a qual prevê o aumento percentual do salário conforme a obtenção de titulações acadêmicas superiores. Observa-se, portanto, a importância deste estudo por convergir pontos de áreas distintas, porém completares, fato que denota seu caráter inovador.

\section{METODOLOGIA}

O presente trabalho constitui-se de uma pesquisa descritiva, que observa e registra fatos, sem interferência do pesquisador, sendo utilizada sobremaneira nas ciências humanas e sociais (CERVO; BERVIAN, 1983). Iniciou-se, contudo, por uma pesquisa bibliográfica que, conforme Marconi e Lakatos (2014), objetiva introduzir ao pesquisador todo o conhecimento já produzido acerca de dado objeto de pesquisa, possibilitando a construção de um referencial sólido, que sustente adequadamente a investigação, a partir de sua problematização. Dessa forma, o referencial teórico constitui-se de suas seções: i) motivação e desenvolvimento de competências e ii) carreira dos servidores TAE.

As informações foram extraídas de sistemas informatizados utilizados em diversos setores administrativos da UFSJ, predominantemente do Sistema Integrado de Gestão de Recursos Humanos (SigRG), e também, a título de complementação, do Sistema Integrado de Administração de Recursos Humanos (Siape), sendo este último do Ministério do Planejamento Orçamento e Gestão (MPOG), conforme disposto na Tabela 1.

Tabela 1 - Origem dos dados

\begin{tabular}{l|l}
\hline \multicolumn{1}{c|}{ Dados } & Fonte \\
\hline $\begin{array}{l}\text { Quantitativo de servidores docentes e } \\
\text { técnicos administrativos que integram } \\
\text { o quadro permanente de pessoal da } \\
\text { UFSJ }\end{array}$ & \\
\hline Idade $^{1}$ & \multirow{2}{*}{ SigRH } \\
\cline { 1 - 1 } Tempo de serviço público prestado à & \\
União2 & \\
\hline Níveis de classificação na carreira3 & \\
\hline Níveis de escolaridade4 & \\
\hline Fon & \\
\hline
\end{tabular}

Fonte: elaborado pelos autores.

A análise de dados combina as metodologias quantitativa e qualitativa, visando traçar o perfil fidedigno da população em estudo, bem como analisar o contexto que estimula a formação deste perfil (SANTOS, 2009). Assim, os quantitativos extraídos dos sistemas supracitados foram transformados em números percentuais ou extraiu-se sua média aritmética simples, operações que permitiram a comparação e análise dos dados, por meio da triangulação da teoria ora exposta.

\section{REFERENCIAL TEÓRICO}

\subsection{MOTIVAÇÃO E DESENVOLVI- MENTO DE COMPETÊNCIAS}

A priori, as organizações foram vistas como ambientes mecânicos, em que não havia espaço para valores humanos. Não apenas as decisões eram centralizadas, como todo o conhecimento acerca do processo produtivo, havendo distinção entre os que planejavam e os que executavam. A Abordagem Humanística contesta esta visão, na medida em que acredita residir na força de trabalho humano um dos diferenciais estratégicos da organização (REED, 2007). Rocha (2005) corrobora, ao defender 
que tanto as organizações não são máquinas, como os funcionários igualmente não se neutralizam mediante as políticas institucionalizadas, o que, contudo, pode afastá-los das regras e objetivos impostos.

Em compasso com a teoria, os métodos de gestão organizacional têm sofrido drásticas mudanças, em razão das crescentes pressões externas, advindas de sindicatos, governos e mídia, entre outros atores sociais, e do aumento da competição em escala mundial, com o advento da globalização (DUTRA, 2011). Assim, há anos, a área de gestão de pessoas abandonou seu papel meramente burocrático, ampliando seu rol de responsabilidades e buscando, por meio da valorização e motivação dos trabalhadores, a concretização dos interesses institucionais. Penna (1980) define motivação como as alterações comportamentais de um indivíduo mediante a concessão/privação de determinados estímulos. Estes podem ser extrínsecos ou intrínsecos, sendo que os primeiros se encontram, por exemplo, no ambiente organizacional e nas relações interpessoais, ao passo em que os demais se referem às percepções e desejos dos indivíduos (CASTRO, 2002).

Diante de sua relevância, a dificuldade que se imprime no estabelecimento de programas de motivação é de tamanha complexidade, em virtude da variabilidade de métodos para tal, de sua banalização com o decorrer do tempo e do caráter personalíssimo que assumem diante das expectativas individuais e dos diferentes contextos organizacionais. $\mathrm{Na}$ área pública, incentivos são criados visando à melhoria no desempenho e o consequente atendimento dos interesses do principal pelo agente (MATIAS-PEREIRA, 2010). Entretanto, a análise e a avaliação de tais políticas é ainda mais problemática, tendo em vista os múltiplos objetivos da máquina pública e as distintas métricas de eficiência e eficácia.

França (2008) acredita que o principal recurso de que as organizações dispõem para atrair e motivar seus trabalhadores é a recompensa financeira. As teorias e pesquisas motivacionais (HERZBERG; MAUSNER; SYDERMAN,
2011; MASLOW, 2000; MCGREGOR, 1980), contudo, apontam que esta, isoladamente não é capaz de manter a motivação dos indivíduos, mas poderá fazê-lo quando associada a outros atributos, como estabilidade, reconhecimento pessoal e profissional, realização de tarefas desafiadoras e acesso a programas de desenvolvimento (DIFINI, 2002; FERREIRA et al., 2015).

A respeito da valorização do trabalhador, Magalhães et al. (2010) atentam para a importância do desenvolvimento de suas competências alinhadas aos objetivos da organização, de forma que estes estejam aptos para o exercício de suas atividades e sintam-se dispostos a contribuir para o crescimento institucional, uma vez que o treinamento impacta positivamente seu desempenho e motivação. Nas instituições públicas, esta necessidade é ainda mais latente, pois quando da seleção por meio de concurso de provas ou provas e títulos, é possível mensurar apenas de maneira limitada os conhecimentos, habilidades e atitudes dos candidatos (DUARTE; FERREIRA; LOPES, 2009), o que torna ainda mais relevante a formulação de planos de capacitação e qualificação.

O Decreto 5.825/2006 define capacitação como um processo contínuo de aprendizagem, que objetiva ao desenvolvimento de competências individuais que, por sua vez, contribuam para o desenvolvimento de competências institucionais; qualificação como a obtenção de conhecimentos e habilidades por meio de sistemas formais de educação, utilizando-os para o desenvolvimento individual e organizacional; e educação formal como aquela ofertada por instituições formais de ensino (públicas ou privadas), nos diversos níveis de formação, da educação básica à superior (BRASIL, 2006a).

Assim, na expectativa de associar fatores de desenvolvimento, valorização e motivação de seus servidores, desde 2005, o Governo Federal vem intensificando suas políticas de capacitação e qualificação, sempre vinculadas a retribuições salariais, conforme apresentado na seção seguinte. 


\subsection{CARREIRA DOS SERVIDORES TAE}

Segundo Schuster e Dias (2012), o plano de carreira auxilia na organização e estruturação do quadro de pessoal de uma organização, proporcionando atratividade de talentos e visibilidade perante o mercado de trabalho. Relaciona-se ainda com fatores motivacionais extrínsecos, essenciais para a retenção de pessoal qualificado e influenciado no alcance de metas institucionais.

O Regime Jurídico do Servidor Público, na forma da Lei Federal 8.112/1990, abrange todo o funcionalismo federal e define servidor público como a pessoa responsável por atribuições previstas na estrutura organizacional de uma instituição pública, legalmente investido em cargo que exige, entre outros requisitos, um nível mínimo de escolaridade (BRASIL, 1990).

Já o texto da Lei Federal 11.091/2005 dispõe especificamente sobre o plano de carreira dos servidores TAE (PCCTAE), instituindo regulamentos para a atuação das instituições de ensino e criando mecanismos que estimulem a busca por capacitação e qualificação por estes servidores. A carreira está organizada em cinco níveis de classificação, que vão de $\mathrm{A}$ a $\mathrm{E}$, cada um com 4 níveis de capacitação, I a IV, e 16 padrões de vencimento. $\mathrm{O}$ servidor TAE terá duas formas de progressão (por capacitação e mérito; - a primeira, decorrente da apresentação de certificados de cursos de pequena duração e a segunda mediante obtenção de aproveitamento mínimo em avaliação de desempenho), ambas com interstício de 18 meses. A mudança de nível de classificação, contudo, somente se dará mediante aprovação em outro concurso (BRASIL, 2005b).

Em seu artigo $3^{\circ}$, incisos III e VII, a supramencionada Lei afirma que os planos de carreira serão estruturados tendo em vista, também, a qualidade de vida no trabalho e o desenvolvimento do servidor em consonância com os objetivos organizacionais (BRASIL, 2005b). Em consenso, o Decreto Federal 5.707/2006, que institui a Política Nacional de Desenvolvimento de Pessoal, aponta que este deverá buscar o aumento da efetividade e qualidade dos serviços públicos e ainda o contínuo desenvolvimento dos servidores (BRASIL, 2006b). Assim, Fonseca e Ferreira (2011) afirmam que o entendimento a respeito do desenvolvimento do servidor deve ser ampliado para abranger não apenas a aquisição de competências que melhorarão seu desempenho e o alcance de objetivos institucionais como para a mudança cultural e a melhoria da qualidade de vida no ambiente organizacional.

O PCCTAE institui ainda que o servidor perceberá um percentual sobre seu vencimento básico, denominado incentivo à qualificação, pela apresentação de titulação superior à exigida para ingresso no cargo. Os percentuais não são cumulativos, e o servidor faz jus apenas ao que corresponder ao maior nível de formação. Há ainda a distinção entre formações com relação direta e indireta ao ambiente organizacional e às atribuições do cargo - exceto para o nível fundamental e médio, definidas no anexo III do Decreto $5.824 / 2006$ (BRASIL, 2006c), resultando em diferentes percentuais de incentivo em cada um dos casos, conforme apresentado pela Tabela 2.

Tabela 2 - Percentuais de Incentivo à Qualificação

\begin{tabular}{l|l|l}
\hline $\begin{array}{l}\text { Nível de escolaridade formal superior ao previsto para } \\
\text { exercício do cargo (curso reconhecido pelo MEC) }\end{array}$ & $\begin{array}{l}\text { Área do conhecimento } \\
\text { com relação direta }\end{array}$ & $\begin{array}{l}\text { Área do conhecimento } \\
\text { com relação indireta }\end{array}$ \\
\hline Ensino fundamental completo & $10 \%$ & - \\
\hline Ensino médio completo & $15 \%$ & - \\
\hline $\begin{array}{l}\text { Ensino médio profissionalizante ou ensino médio com } \\
\text { curso técnico completo }\end{array}$ & $20 \%$ & $10 \%$ \\
\hline Curso de graduação completo & $25 \%$ & $15 \%$ \\
\hline Especialização, com carga horária superior a 360h & $30 \%$ & $20 \%$ \\
\hline Mestrado & $52 \%$ & $35 \%$ \\
\hline Doutorado & $75 \%$ & $50 \%$ \\
\hline
\end{tabular}

Fonte: (BRASIL, 2012, online). 
Tendo em vista todas as imposições apresentadas, como interstício para a progressão na carreira e impossibilidade de mudança de cargo sem a aprovação em novo concurso, em outras palavras, diante de seu caráter rígido e limitador, Souza e Antunes (2015) questionam se este plano de carreira não é mero desenho de cargos e salários.

\section{APRESENTAÇÃO DOS RESULTA- DOS}

\subsection{PERFIL DOS TÉCNICO-ADMINIS- TRATIVOS NA UFSJ}

A Fundação de Ensino Superior de São João Del Rei (Funrei), instituída pela Lei Federal 7.555/1986, era pessoa jurídica de direito privado, com quadro de pessoal regido pela Consolidação das Leis do Trabalho (CLT). A Fundação era mantenedora das Faculdades de Ciências Econômicas, Administrativas e Contábeis; Engenharia Industrial; e Faculdade Dom Bosco de Filosofia, Ciências e Letras, sendo responsável ainda pelo desenvolvimento da pesquisa, artes, ciências e letras (BRASIL, 1986). Em 2002, por meio da Lei Federal 10.425/2002, a Funrei torna-se Fundação Universidade Federal de São João del-Rei (UFSJ), cujo objetivo passa a ser a oferta de ensino superior, pesquisa e extensão. A UFSJ, agora pessoa jurídica de direito público, permanece vinculada ao Ministério da Educação, tendo suas atividades financiadas, precipuamente, pelo Governo Federal (BRASIL, 2002).

A UFSJ possui seis campus, três deles (incluindo a sede) no município de São João del-Rei, e os demais nos municípios de Divinópolis, Ouro Branco e Sete Lagoas, todos no estado de Minas Gerais. Conforme o Relatório UFSJ em Números apresentado em 2011, naquele ano, foram matriculados 10.268 discentes para cursos de graduação presencial, sendo 2.850 ingressantes, distribuídos entre as vagas diurnas e noturnas. Os alunos matriculados nos cursos de pós-graduação stricto sensu somavam 432 discentes, enquanto aqueles matricu- lados em pós-graduação lato sensu chegavam a 2.868. A graduação a distância oferecia 1.500 vagas, ao passo em que a pós lato sensu oferecia 2.890. No mesmo ano, havia 594 projetos de pesquisa em andamento e 2.202 programas de extensão, que atingiam um público de 525.339 pessoas (UNIVERSIDADE FEDERAL DE SÃO JOÃO DEL-REI, 2011b). Esses dados ratificam a necessidade de incremento estrutural nas IFE diante da ampliação de suas atividades.

A comunidade universitária é composta por docentes, técnicos administrativos e discentes (UNIVERSIDADE FEDERAL DE SÃO JOÃO DEL-REI, 2005, 2011b). Suas atividades pedagógicas são executadas por docentes e embasadas pelas atividades periféricas dos técnicos administrativos em educação (TAE) das mais diversas áreas de formação. Apesar do maior quantitativo de docentes, as atividades fins (pedagógicas) e meio (administrativas) são indissociáveis e igualmente importantes para a continuidade e qualidade dos serviços prestados (SCHMITZ JUNIOR et al., 2016). A distribuição percentual do quadro permanente de pessoal está evidenciada na Tabela 3.

\begin{tabular}{|c|c|c|}
\hline- & Docentes & TAE \\
\hline Quantidade & 837 & 540 \\
\hline $\begin{array}{c}\text { Representação } \\
\text { percentual aproximada }\end{array}$ & $61 \%$ & $39 \%$ \\
\hline
\end{tabular}

Fonte: (SigRH, 2017).

No Estatuto da UFSJ, em seu Título IV, Capítulo II, Artigo 42, está previsto que as atividades de apoio técnico, administrativo e operacional, fundamentais para o alcance dos objetivos organizacionais, são executadas pelo corpo técnico-administrativo (UNIVERSIDADE FEDERAL DE SÃO JOÃO DEL-REI, 2011a). A respeito da qualificação desses servidores, o Regimento da UFSJ, em seu Título IX, Capítulo II, artigos 133 e 136, ratifica o compromisso da Universidade com sua capacitação, nos termos da lei (UNIVERSIDADE FEDERAL DE SÃO JOÃO DEL-REI, 2005). 
A respeito do disposto no PCCTAE, leis e decretos contemporâneos e subsequentes, nas Tabelas 3 a 6, apresentamos a divisão dos TAE em dois grupos: o primeiro possui tempo de permanência no serviço público superior a 12 anos (e, portanto, ingressou antes das supramencionadas legislações); o segundo grupo possui tempo de permanência no serviço público igual ou inferior a 12 anos, tendo ingressado após o pacote PCCTAE. ve entrada de servidores na carreira TAE nos níveis de classificação A e B, extintos pela Lei $11.091 / 2005$, e ainda que o número de novos servidores no nível $\mathrm{C}$ diminuiu, ao passo que, nos níveis $\mathrm{D}$ e $\mathrm{E}$ houve aumento proporcional.

Dos 540 TAE ativos, 262 são mulheres, assim distribuídas entre os 5 níveis de classificação: 6 em A (1,11\% do total), 32 em C (5,92\% do total), 179 em D (33,14\% do total)

Tabela 4 - Servidores TAE antes e depois do pacote PCCTAE

\begin{tabular}{l|l|l}
\hline Tempo de permanência & $>12$ anos & $\leq 12$ anos \\
\hline Quantidade de servidores & 133 & 407 \\
\hline Tempo de União & 13 a 39 anos & 0 a 12 anos \\
\hline Média de tempo de União & 26,29 anos & 4,99 anos \\
\hline Idade & 38 a 68 anos & 22 a 62 anos \\
\hline Média da idade & 53,79 anos & 36,48 anos \\
\hline
\end{tabular}

Fonte: (SigRH, 2017).

Conforme a Tabela 4, observa-se que aproximadamente $75 \%$ dos TAE da UFSJ ingressaram no serviço público após a aprovação da Lei Federal 11.091/2005, possuindo de meses a 12 anos de permanência, enquanto os outros $25 \%$ estão de 13 a 39 anos no serviço público. A variação de idade dos ingressantes após 2005 é maior (40 anos contra 30 para os ingressantes anteriores a 2005), embora a média de idade dos dois grupos seja bem discrepante (36,48 anos contra 53,79 anos). e 45 em E (8,33\% do total). Assim, a predominância feminina concentra-se nos níveis $\mathrm{A}, \mathrm{C}$ e E, enquanto a masculina no nível D. Não há servidoras ativas no nível $\mathrm{B}$.

Tabela 5 - Distribuição dos TAE conforme os níveis de classificação

\begin{tabular}{c|c|c|c|c}
\hline \multirow{2}{*}{ Nível de classificação } & \multicolumn{2}{|c|}{$>12$ anos } & \multicolumn{2}{c}{12 anos } \\
\cline { 2 - 5 } & Quantidade & $\%$ & Quantidade & $\%$ \\
\hline A & 11 & 2,03 & - & - \\
\hline B & 10 & 1,85 & - & - \\
\hline C & 40 & 7,40 & 23 & 4,25 \\
\hline E & 51 & 9,44 & 323 & 59,81 \\
\hline
\end{tabular}

Fonte: (SigRH, 2017).

A Tabela 5 indica que o nível de classificação $\mathrm{D}$ é o que concentra o maior número de TAE ativos da UFSJ $(69,25 \%)$, seguido dos níveis E (15,17\%), C (11,65\%), A (2,03\%) e B $(1,85 \%)$, nesta ordem. Observa-se que não hou- 
Tabela 6 - Distribuição dos TAE conforme escolaridade

\begin{tabular}{|c|c|c|c|c|}
\hline \multirow{2}{*}{ Escolaridade } & \multicolumn{2}{|c|}{$>12$ anos } & \multicolumn{2}{|c|}{$\leq 12$ anos } \\
\hline & Quantidade & $\%$ & Quantidade & $\%$ \\
\hline Fundamental incompleto & 6 & 1,11 & - & - \\
\hline Fundamental completo & 22 & 4,07 & - & - \\
\hline Médio & 16 & 2,96 & 29 & 5,37 \\
\hline Técnico & 8 & 1,48 & 10 & 1,85 \\
\hline Graduação & 12 & 2,22 & 89 & 16,48 \\
\hline Especialização & 56 & 10,37 & 195 & 36,11 \\
\hline Mestrado & 12 & 2,22 & 80 & 14,81 \\
\hline Doutorado & 1 & 0,18 & 4 & 0,74 \\
\hline
\end{tabular}

Fonte: (SigRH, 2017).

A Tabela 6 nos apresenta a divisão dos TAE conforme seus níveis de educação formal. Os maiores percentuais encontram-se na graduação $(18,73 \%)$, especialização $(46,48 \%)$ e mestrado $(17,03)$. Observemos que o número de graduados, especialistas e mestres ingressantes no serviço público após 2005 supera em mais de $700 \%, 300 \%$ e $600 \%$, respectivamente, os servidores TAE neste mesmo nível de formação que já estavam no serviço público antes da aprovação do PCCTAE e que permanecem ativos. $\mathrm{O}$ nível mínimo de escolaridade dos TAE antes do PCCTAE é o fundamental incompleto e passa a ser o médio completo para os ingressantes dos últimos 12 anos, o que se justifica não apenas pela extinção dos níveis de classificação A e B, que concentram cargos com exigência de menor nível de escolaridade para ingresso, como pela pressuposta e desejada mudança cultural idealizada pelo PCCTAE.
A partir da análise da Tabela 7 nota-se que a média de idade dos servidores ingressantes antes do PCCTAE tem variação inferior a oito anos, o que leva a pressupor que não necessariamente estes servidores foram impulsionados pela Lei a buscar sua qualificação. Observa-se que a maior idade média se encontra no nível fundamental incompleto, sendo que todos os demais servidores, apesar de menos idade, buscaram qualificar-se em outros níveis de educação formal.

\section{CONSIDERAÇÕES FINAIS}

O presente estudo partiu do pressuposto de que os trabalhadores se motivam para o exercício de suas atividades costumeiras e para o alcance dos objetivos organizacionais, não somente, mas também, pelas recompensas salariais. No contexto da educação pública superior

Tabela 7 - Idade média dos TAE conforme nível de escolaridade

\begin{tabular}{l|l|l}
\hline Escolaridade & $>12$ anos & $\leq 12$ anos \\
\hline Fundamental incompleto & 57,90 & - \\
\hline Fundamental completo & 56,80 & - \\
\hline Médio & 57,25 & 35,34 \\
\hline Técnico & 54,50 & 29,00 \\
\hline Graduação & 51,83 & 34,93 \\
\hline Especialização & 51,89 & 37,90 \\
\hline Mestrado & 50,25 & 35,92 \\
\hline Doutorado & 57,00 & 39,50 \\
\hline
\end{tabular}

Fonte: (SigRH, 2017). 
e técnica no Brasil, a Lei Federal 11.091/2005 (BRASIL, 2005b) institui, entre outros pontos, o pagamento de um percentual sobre o vencimento base conforme a apresentação de titulação superior àquela exigida para o ingresso em cargo público; em outras palavras, estabelece o incentivo à qualificação. Tal concessão respalda-se nos preceitos anteriormente elencados de que este se tornará mais assertivo e colaborativo na medida em que receber estímulos apropriados - tanto em nível de ampliação de suas competências, como de seu salário. Por conseguinte, o trabalhador qualificado e motivado estará apto a prestar um serviço de melhor qualidade ao usuário, em consenso com a busca de eficiência e eficácia governamental.

O levantamento de dados realizado possibilitou retratar o perfil dos servidores TAE da UFSJ sob a perspectiva de sua formação escolar, 12 anos após a promulgação do Plano de Carreira, o PCCTAE.

Os dados comprovam a complexidade e a dificuldade de se instituírem políticas motivacionais diante de aspectos diversos mas, sobretudo, devido às percepções e desejos de cada indivíduo. Assim, retomando a pergunta norteadora deste trabalho, tem-se que as retribuições em pecúnia, instituídas pela Lei, relacionam-se diretamente com os níveis de escolaridade dos servidores ingressantes na União após sua promulgação, o que não se deu, entretanto, com a maioria dos servidores que já se encontravam em exercício à época.

A título de exemplificação, tem-se, de um lado, indivíduos com idade média inferior a 40 anos e média aproximada de 5 anos de prestação de serviços à União, com titulação de doutor; de outro lado, tem-se servidores cuja média de idade supera os 57 anos e que se encontram no serviço público há mais de 26 anos, em média, mas possuem nível fundamental incompleto de instrução, apesar da possibilidade de aumento salarial instituído pelo PCCTAE a partir de 2005.

Oportunizou-se, em seções anteriores, apontar a importância de se estimular o desenvolvimento de competências pelos servidores em consonância com os objetivos organizacionais. As legislações trazidas firmam o compromisso de primar pela qualidade de vida no trabalho, bem como buscar, por meio do incremento de know-how dos servidores, o aumento da efetividade e da qualidade organizacional. Observa-se, portanto, um ainda incipiente esforço do Governo Federal no sentido de promover a capacitação e qualificação de seus servidores, vistas a associar o desenvolvimento, a valorização e a motivação desses trabalhadores, atreladas a retribuições salariais.

Apesar dos avanços percebidos no que tange à proposta da Lei, é importante reconhecer as limitações das políticas de gestão de pessoas no serviço público. O simples fato de os TAE estarem apresentando maiores níveis de escolaridade, por si só, não coaduna com os objetivos organizacionais, os quais não constituíam objeto de investigação deste estudo. Em outras palavras, os técnico-administrativos podem estar buscando qualificar-se objetivando apenas ao aumento salarial, de forma que não necessariamente suas competências estarão sendo aplicadas no cotidiano institucional.

Além disso, é fundamental que, após o processo de qualificação, haja uma busca da instituição pela constante manutenção do estado de motivação do servidor. Constitui-se um desafio enriquecer cargos que exigem pouca escolaridade, assim como é difícil motivar o servidor que atingiu um alto nível de qualificação, uma vez que as atividades administrativas e operacionais podem tornar-se monótonas, não havendo espaço para aplicação das competências adquiridas.

Diante de tais limitações, sugerem-se a realizações de estudos futuros que sejam capazes de complementar a presente investigação: i) realização de entrevistas com amostra estratificada de servidores, fins de inquirir os estímulos necessários para sua qualificação; ii) estudo comparativo do perfil acadêmico dos TAE em um recorte temporal que compreenda anos antes e após a Lei Federal 11.091/2005; iii) levantamento acerca da existências de programas internos às IFES que instiguem no téc- 
nico-administrativo o desejo de qualificar-se, como cursos de graduação e pós-graduação com percentual de vagas a eles destinadas. Por fim, espera-se que os resultados apresentados sejam capazes de gerar reflexões acerca do processo de qualificação, tanto nos servidores técnico-administrativos quanto nos gestores das Instituições Federais de Ensino.

\section{AN ANALYSIS OF THE PROFILE OF THE TECHNICAL AND ADMINISTRATIVE EMPLOYEES OF FEDERAL UNIVERSITY AFTER THE ENTRY INTO FORCE OF FEDERAL LAW 11.091/2005}

\section{ABSTRACT}

Ever since they started viewing employees as a differential in competitiveness, organizations began working on employee motivation and development. Federal universities have developed career plans, aimed at qualifying their employees, trying to improve the effectiveness of their actions. The objective of this work is to establish the profile of the technical and administrative employees (TAE) of the Federal University of São João del-Rei, twelve years after the entry into force of Federal Law 11.091/2005, which establishes financial benefits for those TAE that receive an education degree above the one required for entry into such functions. This case study is a descriptive research, which was carried out through quantitative-qualitative analysis of the data extracted from computer systems used by the University. We observed that the above-mentioned law influenced the employees that took up post after 2005 to seek higher levels of education, even if the same was not observed in those who were already in the public service at said date; this leads to the conclusion that there has been a gradual change in the culture of these institutions.

Keywords: Qualification. Career plan. Technical-administrative employees in education.

\section{UN ANÁLISIS DEL PERFIL DE LOS SERVIDORES TÉCNICO- ADMINISTRATIVOS DE UNA UNIVERSIDAD FEDERAL DESPUÉS DE LA PROMULGACIÓN DE LA LEY FEDERAL 11.091/2005}

\section{RESUMEN}

Desde que percibieron el trabajador como un diferencial competitivo, las organizaciones pasaron a buscar su motivación y desarrollo. Las instituciones federales de enseñanza desarrollaron planos de carrera, objetivado a capacitar y a cualificar sus servidores, visando a dar más efectividad a sus acciones. El objeto de este trabajo es de establecer el perfil de los servidores técnico-administrativos de la Universidad Federal de São João del-Rei, 12 años después de la promulgación de la Ley Federal 11.091/2005, que concede incentivos financieros conforme la obtención de titulaciones superiores a aquellas exigidas para ingresar en los cargos. Este levantamiento es una investigación descriptiva, que realizó análisis cuantitativo-cualitativo de los datos extraídos de los sistemas de computadora utilizados por la Universidad. Se observó que la mencionada ley influenció los servidores que ingresaron a partir de 2005 a buscar más altos niveles de instrucción, aunque no haya influenciado los que ya estaban en el servicio público en esa data, lo que nos lleva a inferir que hay habido un cambio gradual en la cultura de esas instituciones.

Palabras-clave: Cualificación. Plan de carrera. Servidor técnico-administrativo en educación. 


\section{L'ANALYSE DU PROFIL DES FONCTIONNAIRES TECHNIQUES ET ADMINISTRATIFS D'UNE UNIVERSITÉ FÉDÉRALE APRÈS LA PROMULGATION DE LA LOI FÉDÉDRALE 11.091/2005}

\section{RESUME}

Depuis que les organizations se sont aperçues que les travailleurs sont un différentiel compétitif, elles ont passé à chercher leur motivation et leur développement. Les institutions fédérales d'enseignement ont développé des plans de carrières, avec l'objectif de capaciter et de qualifier leurs fonctionnaires, pour donner plus d'efficacité à leurs actions. L'objet de ce travail est d'établir le profil des fonctionnaires techiniques et administratifs de l'Université Fédérale de São João del-Rei, douze ans après la promulgation de la Loi Fédérale 11.091/2005, qui accorde des avantages financiers selon l'obtention de diplômes supérieurs à ceux qui sont exigés pour entrer en fonction dans ces postes. Cette étude est une recherche descriptive, qui a réalisé une analyse quantitative et qualitative des données extraites des systèmes informatiques utilisés par l'université. Il a été observé que la loi susmentionnée a influencé les fonctionnaires qui ont pris leurs fonctions après 2005 à cherches des plus hauts niveaux d'instructions, malgré le fait qu'elle n'ait pas eu la même influence sur ceux qui étaient déjà au service public à cette époque, ce qui nous amène à la conclusion qu'il y a un changement graduel de la culture de ces institutions.

Mots-clés: Qualification. Plan de carrière. Fonctionnaire techinique et adminsitratif em éducation.

1 Dados referentes ao servidores da UFSJ, seccionados conforme o ano de publicação da Lei Federal 11.091/2005 (BRASIL, 2005b).

\section{REFERÊNCIAS}

ARRETCHE, Marta T. S. Tendências no estudo da avaliação. In: RICO, E. M. (Org.). Avaliação das políticas sociais: uma questão em debate. São Paulo, Cortez, 1999. p. 29-39.

BRASIL. Decreto ${ }^{0} 5.707$, de 23 de fevereiro de 2006. Institui a Política e as Diretrizes para o Desenvolvimento de Pessoal da administração pública federal direta, autárquica e fundacional, e regulamenta dispositivos da Lei no 8.112, de 11 de dezembro de 1990. Presidência da República, Brasília, DF, 2006b. Disponível em $<$ https:// goo.gl/XXsX4c>. Acesso em: 17 maio 2017.

Decreto $\mathrm{n}^{\mathrm{o}} 5.824$, de 29 de junho de 2006. Estabelece os procedimentos para a concessão do Incentivo à Qualificação e para a efetivação do enquadramento por nível de capacitação dos servidores integrantes do Plano de Carreira dos Cargos Técnico-Administrativos em Educação, instituído pela Lei no 11.091, de 12 de janeiro de 2005. Presidência da República, Brasília, DF, 2006c. Disponível em: <https:// goo.gl/p6KAIw>. Acesso em: 17 maio 2017.

Decreto $n^{\circ} 5.825$, de 29 de junho de 2006. Estabelece as diretrizes para elaboração do Plano de Desenvolvimento dos Integrantes do Plano de Carreira dos Cargos Técnico-Administrativos em Educação, instituído pela Lei no 11.091 , de 12 de janeiro de 2005. Presidência da República, Brasília, DF, 2006a. Disponível em: <https://goo.gl/SrxxTW $>$. Acesso em: 17 maio 2017.

Decreto $^{\circ}$ 6.096, de 24 de abril de 2007. Institui o Programa de Apoio a Planos de Reestruturação e Expansão das Universidades Federais REUNI. Presidência da República, Brasília, DF, 2007. Disponível em: <https://goo.gl/uNYPIz>. Acesso em: 30 maio 2017.

. Lei $\mathrm{n}^{\circ} 7.555$, de 18 de dezembro de 1986. Autoriza o Poder Executivo a instituir a Fundação de Ensino Superior de São João Del Rei e dá 
outras providências. Presidência da República, Brasília, DF, 1986. Disponível em: <https://goo. gl/z7mSID>. Acesso em: 23 maio 2017.

Lei $\mathrm{n}^{\circ} 8.112$, de 11 de dezembro de 1990. Dispõe sobre o regime jurídico dos servidores públicos civis da União, das autarquias e das fundações públicas federais. Presidência da República, Brasília, DF, 1990. Disponível em: <https://goo.gl/acJJhu>. Acesso em: 17 maio 2017.

Lei $n^{\circ} 10.425$, de 19 de abril de 2002. Dispõe sobre a transformação da Fundação de Ensino Superior de São João del Rei em Fundação Universidade Federal de São João del Rei, e dá outras providências. Presidência da República, Brasília, DF, 2002. Disponível em: $<$ https:// goo.gl/x6SoAI>. Acesso em: 23 maio 2017.

Lei $\mathrm{n}^{0}$ 11.091, de 12 de janeiro de 2005. Dispõe sobre a estruturação do Plano de Carreira dos Cargos Técnico-Administrativos em Educação, no âmbito das Instituições Federais de Ensino vinculadas ao Ministério da Educação, e dá outras providências. Presidência da República, Brasília, DF, 2005b. Disponível em: <https://goo.gl/F4YcV7>. Acesso em: 17 maio 2017.

Lei $\mathrm{n}^{0}$ 11.096, de 13 de janeiro de 2005. Institui o Programa Universidade para Todos - PROUNI, regula a atuação de entidades beneficentes de assistência social no ensino superior; altera a Lei no 10.891, de 9 de julho de 2004, e dá outras providências. Presidência da República, Brasília, DF, 2005a. Disponível em: <https://goo. gl/WuJ9Tj> . Acesso em: 30 maio 2017.

Lei $\mathrm{n}^{\mathrm{o}} 12.772$, de 28 de dezembro de 2012. Dispõe sobre a estruturação do Plano de Carreiras e Cargos de Magistério Federal; e dá outras providências. Presidência da República, Brasília, DF, 2012. Disponível em: <https:// goo.gl/717bK2>. Acesso em: 19 maio 2017.

CASTRO, Alfredo Pires de. Manual de gestão de pessoas e equipes. São Paulo: Gente, 2002. CERVO, A. L.; BERVIAN, P. A. Metodologia científica. 3. ed. São Paulo: McGraw-Hill, 1983.

COSTA, Frederico Lustosa da; CASTANHAR, J. Cezar. Avaliação de Programas Públicos: desafios conceituais e metodológicos. RAP, Rio de Janeiro, v. 37, n.5, p. 969-992, set./out. 2003. Disponível em: <https://goo.gl/tktYpP>. Acesso em: 27 nov. 2017.

DENHARDT, R. B.; DENHARDT, J. V. The new public service: serving rather than steering. Public Administration Review, United Kingdom, v. 60, n. 6, p. 549-558. dez. 2000. Disponível em: <https://goo.gl/NTqxxU>. Acesso em: 27 nov. 2017.

DIFINI, Cristianismo Esplendor Região. Avaliação da satisfação e motivação dos técnico-administrativos em uma instituição de ensino superior: um estudo de caso. 2002. 86 f. Dissertação (Mestrado Profissional em Engenharia) - Escola de Engenharia, Universidade Federal do Rio Grande do Sul, Porto Alegre. 2002. Disponível em: <https://goo.gl/E6USNB>. Acesso: em 20 jun. 2017.

DONAZAR, Rebeca Campani. A experiência da Universidade Federal do Rio Grande do Sul de gestão da área de capacitação alinhada às políticas nacionais de capacitação e desenvolvimento de servidores. In: COLÓQUIO INTERNACIONAL DE GESTÃO UNIVERSITÁRIA - CIGU, 15., 2015, Mar Del Plata Argentina. Anais... Mar Del Plata - Argentina: UFSC, 2015. Disponível em: <https://goo.gl/ cv28es>. Acesso em: 20 jun. 2017.

DUARTE, Michelle; FERREIRA, Sandra Alberta; LOPES, Suely Pereira. A gestão por competência como ferramenta para o desenvolvimento dos servidores técnico-administrativos: case da Universidade Federal do Tocantins. APGS - Administração Pública e Gestão Social, Viçosa, v. 1, n. 2, p. 101-120, abr./jun. 2009. Disponível em: <https://goo.gl/ 
cxbQNR>. Acesso em: 20 jun. 2017.

DUTRA, Joel Souza. Gestão de pessoas: modelos, processos, tendências e perspectivas. São Paulo: Atlas, 2011.

FERREIRA, Luciana Gonçalves et al. Influência dos incentivos à qualificação dos servidores técnico-administrativos da Universidade Federal de São João Del Rei. Teoria e Prática em Administração, João Pessoa, v. 5, n. 1, p. 183-203, 2015. Disponível em: <https://goo. gl/48HWSH>. Acesso em: 20 jun. 2017.

FONSECA, Márcio Alessandro Teles; FERREIRA, Rosilda Arruda. Desenvolvimento de Pessoas em Instituições Públicas Federais de Ensino: entre o legal e o real. In: COLÓQUIO INTERNACIONAL SOBRE GESTÃO UNIVERSITÁRIA NA AMÉRICA DO SUL, 11., 2011. Florianópolis - Brasil. Anais... Florianópolis, 2011. Disponível em: <https://goo.gl/ P2nwa7>. Acesso em: 3 maio 2017.

FRANÇA, Ana Cristina Limongi. Práticas de recursos humanos: conceitos, ferramentas e procedimentos. São Paulo: Atlas, 2008.

HERZBERG, F.; MAUSNER, B.; SYDERMAN, B. The motivations to work. New Jersey: Transaction Publisher, 2011.

MACÊDO, Kátia Barbosa; PIRES, José Calixto de Souza. Cultura organizacional em organizações públicas no Brasil. RAC - Revista de Administração Contemporânea, Rio de Janeiro, v. 40, n. 1, p. 81-105, jan./fev. 2006. Disponível em: $<$ https://goo.gl/qq8xhc $>$. Acesso em: 19 jun. 2017.

MAGALHÃES, Elenice Maria de et al. A política de treinamento dos servidores técnico-administrativos da Universidade Federal de Viçosa (UFV) na percepção dos treinados e dos dirigentes da instituição. RAP - Revista de Administração Pública, Rio de Janeiro, v. 44, n. 1, p. 55-86, jan./fev. 2010. Disponível em: <https://
goo.gl/4Wqbno>. Acesso em: 20 jun. 2017.

MARCONI, Marina de Andrade; LAKATOS, Eva Maria. Metodologia do trabalho científico. 7. ed. São Paulo: Atlas, 2014.

MASLOW, A. H. Maslow no gerenciamento. Rio de Janeiro, Qualitymark, 2000.

MATIAS-PEREIRA, J. Aplicação da governança na administração pública. In:

Governança NO SETOR Público. São Atlas, 2010. p. 142-146.

MCGREGOR, Douglas. O lado humano da empresa. São Paulo: Martins Fontes, 1980.

PAULA, Ana Paula Paes de. Por uma nova gestão pública: limites e potencialidades da experiência contemporânea. Rio de Janeiro: FGV, 2007.

PENNA, Antônio Gomes. Aprendizagem e motivação. Rio de Janeiro: Zahar Editores, 1980.

REED, Michel. Teorização organizacional: um campo historicamente contestado. In: CALDAS, Miguel; FACHIN, Roberto; FISCHER, Tânia (Org.). Handbook de estudos organizacionais: modelos de análise e novas questões em estudos organizacionais. São Paulo: Atlas, 2007. p. 61-98.

ROCHA, J. A. Oliveira. Quadro geral da evolução da gestão de recursos humanos na administração pública. In: CONFERÊNCIA NO INSTITUTO SUPERIOR DE CONTABILIDADE E ADMINISTRAÇÃO DE LISBOA, 2005, Lisboa. Anais... Lisboa: Instituto Superior de Contabilidade e Administração de Lisboa, 2005. Disponível em: <https://goo.gl/ meMT33>. Acesso em: 28 nov. 2017.

SANTOS, Tânia Steren dos. Do artesanato intelectual ao contexto virtual: ferramentas metodológicas para a pesquisa social. Sociologias, Porto Alegre, v. 11, n. 21, p. 120-156, jan./jun. 
2009. Disponível em: <https://goo.gl/aWRxqC>. Acesso em: 20 jun. 2017.

SARAIVA, Luiz Alex Silva. Cultura organizacional em ambiente burocrático. RAC - Revista de Administração Contemporânea, Rio de Janeiro, v. 6, n. 1, p. 187-207, jan./abr. 2002. Disponível em: <https://goo.gl/KFRr99>. Acesso em: 19 jun. 2017.

SCHMITZ JUNIOR, Salezio et al. Dez anos de políticas públicas de gestão de pessoas para as IFEs: os impactos para os técnico-administrativos em educação. In: COLÓQUIO INTERNACIONAL SOBRE GESTÃO UNIVERSITÁRIA NA AMÉRICA DO SUL, 16., 2016, Arequipa - Peru. Anais... Arequipa, 2016. Disponível em: <https://goo.gl/tnJkgR>. Acesso em: 3 maio 2017.

SCHUSTER, Marcelo da Silva; DIAS, Valéria da Veiga. Plano de carreira nos sistemas de gestão público e privado: uma discussão a luz das teorias motivacionais. Revista de Administração IMED, Passo Fundo, v. 2, n. 1, p. 1-17, mar. 2012. Disponível em: $<$ https://goo. gl/1HgM9r>. Acesso em: 27 nov. 2017.

SLOMSKI, Valmor. Sociedade, estado e teoria do agenciamento. In: Controladoria e Governança na Gestão Pública. São Paulo: Atlas, 2005. p. 20-34.

SOUZA, Irineu Manoel de; ANTUNES, Tereza Cristina Meurer. Plano de carreira dos servidores técnico-administrativos em educação das instituições federais de ensino superior. In: COLÓQUIO INTERNACIONAL SOBRE GESTÃO UNIVERSITÁRIA NA AMÉRICA DO SUL, 11., 2015, Mar del Plata - Argentina. Anais... Mar del Plata, 2015. Disponível em: <https:// goo.gl/EkZaQr>. Acesso em: 3 maio 2017.

TORRES, Marcelo Douglas de Figueiredo. Estado, democracia e administração pública no Brasil. Rio de Janeiro: Editora FGV, 2004.
UNIVERSIDADE FEDERAL DE SÃO JOÃO DEL-REI. Estatuto. São João Del-Rei: UFSJ, 2011a. Disponível em: <https://goo.gl/cQiB3w>. Acesso em: 23 maio 2017.

Regimento geral. São João Del-Rei: UFSJ, 2005. Disponível em: $<$ https://goo.gl/rtn2GS>. Acesso em: 23 maio 2017.

. UFSJ em números. São João Del-Rei: UFSJ, 2011b. Disponível em: <https://goo.gl/ 17TF61>. Acesso em: 23 maio 2017. 